TPeriodica Polytechnica Electrical Engineering and Computer Science

59(3), pp. 94-98, 2015

DOI: $10.3311 /$ PPee. 8604

Creative Commons Attribution (i)

RESEARCH ARTICLE

\section{Analysis of Voltage Stability in Electric Power System with UPFC}

\author{
Samo Gasperic ${ }^{1 *}$, Rafael Mihalic ${ }^{1}$
}

Received 12 June 2015; accepted after revision 21 August 2015

\begin{abstract}
Impact of FACTS devices on the voltage stability is usually determined with the power-flow calculations. Results, gained in this way, is sometimes difficult, if not impossible, to explain in qualitative way and to draw the general conclusions. Therefore analytical approach using simple basic models may submit more insight into basic features of tested device behavior in an electric power system (EPS) than numerical calculations at real-like system model. The paper presents such an approach for Unified Power-Flow Controller (UPFC), which may be considered a synonym for multi-parameter controlled FACTS device. The basic goal is to acquire impact of an UPFC on voltage stability enhancement and voltage control respectively. Therefore it is positioned into the standard model, widely used for voltage stability representation purposes. In the paper the mathematical solution of the problem is explained and the impact of the UPFC on voltage stability is shown.
\end{abstract}

\section{Keywords}

Electric Power System, Voltage Stability, PV Curves, FACTS, UPFC

\section{Introduction}

Consequences of voltage instability can lead into a system blackout in an electric power system (EPS), which can cause a leakage of electricity supply thousands of consumers and millions euros of economical losses. Voltage instability is a well known phenomenon described in Refs. [1-3] and reports [4-8], but less theoretically explained in cases that in the EPS operates a FACTS device (Flexible AC transmission system), such as a static VAr compensator (SVC), a static synchronous compensator (STATCOM), a controllable series compensation (CSC), a static synchronous series compensator (SSSC), a serial-parallel device - unified power-flow controller (UPFC) or others. Ref. [9] explains the impact of parallel and serial FACTS devices on the voltage stability; while the present paper introduces the mathematical background and analyses the impact of the UPFC on voltage stability in the EPS.

The UPFC device combines the features of a serial device SSSC, a parallel device STATCOM and a phase-shifting transformer in one device. The UPFC has three independently controllable parameters and can operate in different ways [10-12]:

- a simultaneous and independent power-flow control of the transmission line,

- a simultaneous and independent voltage control,

- an optimal operation of an EPS based on a transmission angle and a power-flow control,

- improving angle and voltage stability,

- direct voltage injection,

- a voltage regulation in the selected busbar,

- a compensation of the line impedance,

- a phase angle control and others.

Figure 1, adopted from [9, 12], illustrates the basic structure of an UPFC which consists of two frequency converters: a parallel transformer (denoted as TRP) with a frequency converter 1 and a serial transformer (denoted as TRS) with a frequency converter 2 . The converter 1 and 2 are operated from a common DC link provided by a DC storage capacitor: parallel $\mathrm{CP}$ and serial CS condenser battery. The ideal conversion $\mathrm{AC}-\mathrm{DC}-\mathrm{AC}$ between the converter 1 and 2 provide an
${ }^{1}$ Department of Electric Power System and Devices,

Faculty of Electrical Engineering, University of Ljubljana,

SI-1000 Ljubljana, Trzaska 25, Slovenia

*Corresponding author, e-mail: samo.gasperic@fe.uni-lj.si 
independent generation or absorption of a reactive power at each converter output.

The serial branch (converter 2 and TRS) injects in the line a voltage phasor $\underline{U}_{\mathrm{T}}$ with controllable magnitude $U_{\mathrm{T}} \in\left[0, U_{\mathrm{T} \max }\right]$ and angle $0^{\circ} \leq \varphi_{\mathrm{T}} \leq 360^{\circ}$. If the phasor $\underline{U}_{\mathrm{T}}$ leads the line current $\underline{I}_{\mathrm{UPFC}}$ it causes an effect of into a line connected parallel inductance and in case the phasor $\underline{U}_{\mathrm{T}}$ lags the current $\underline{I}_{\mathrm{UPFC}}$ an effect is as parallel to the line connected capacitor.

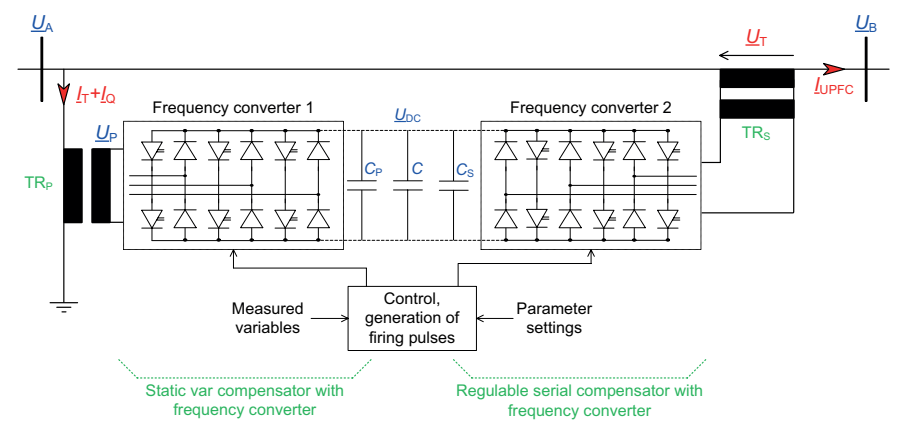

Fig. 1 The principle sketch of the UPFC.

The parallel branch controls an injection of a capacitive or an inductive reactive power into the grid which affects a voltage phasor $\underline{U}_{\mathrm{A}}$. A current phasor $\underline{I}_{\mathrm{Q}}$ of the parallel branch denotes the reactive current that can lead or lag the voltage phasor $\underline{U}_{\mathrm{A}}$ for 90 degrees.

The frequency converter 1 adjusts the active power by controlling an angle between the phasor $\underline{U}_{\mathrm{A}}$ and $\underline{U}_{\mathrm{P}}$ by the parallel branch.

The UPFC itself does not produce any active power; the equilibrium of the active power is achieved by injection into or from the parallel branch with the transformer $\mathrm{TR}_{\mathrm{P}}$ with the frequency converter 1 . The active power of the serial converter is provided by a current $I_{\mathrm{T}}$ from the parallel branch in accordance with:

$$
\begin{gathered}
\underline{U}_{A} \cdot \underline{I}_{\mathrm{T}}^{*}=\operatorname{Re}\left[\underline{U}_{\mathrm{T}} \cdot \underline{I}_{\mathrm{UPFC}}^{*}\right], \\
\underline{I}_{\mathrm{T}} \| \underline{U}_{\mathrm{A}} .
\end{gathered}
$$

The real part $\operatorname{Re}\left[\underline{U}_{\mathrm{T}} \cdot \underline{I}_{\mathrm{UPFC}}^{*}\right]$ is an active power that is transferred from the parallel branch $\underline{U}_{\mathrm{A}} \cdot \underline{I}_{\mathrm{T}}^{*}$ and is injected by the serial branch into the EPS. The current phasor $\underline{I}_{\mathrm{T}}$ in Figs. 1 and 2 has only real component $\operatorname{Re}\left[\underline{I}_{\mathrm{T}}\right]$ and is in phase with the voltage $\underline{U}_{\mathrm{A}}$. The phasor $\underline{I}_{\mathrm{T}}$ illustrates a transfer of active power $\underline{U}_{\mathrm{A}} \cdot \underline{I}_{\mathrm{T}}^{*}$ from the parallel into the serial branch (1).

The parallel branch controls the reactive power independently of the serial branch, with the assumption that the current in the serial branch $\left(\underline{I}_{\mathrm{T}}+\underline{I}_{\mathrm{Q}}\right)$ is independent of the voltage $\underline{U}_{\mathrm{A}}$. The balance of the reactive power is achieved with the introduction of the current phasor $\underline{I}_{\mathrm{Q}}$ :

$$
\underline{I}_{\mathrm{Q}} \perp \underline{I}_{\mathrm{T}},
$$

$$
\underline{I}_{\mathrm{Q}}=\mathrm{j} B_{\mathrm{Q}} \cdot \underline{U}_{\mathrm{A}} .
$$

The phasor $\underline{I}_{\mathrm{Q}}$ is in addition to $U_{\mathrm{T}}$ and $\varphi_{\mathrm{T}}$ the third parameter of the UPFC [10]. In mathematical derivation the current $I_{\mathrm{Q}}$ is expressed with the susceptance $B_{\mathrm{Q}}$ that enables the analytical solutions of equations. The sum of the currents $I_{\mathrm{Q}}$ and $\underline{I}_{\mathrm{T}}$ of the parallel branch is denoted as $\underline{I}_{\mathrm{PAR}}$.

$$
\underline{I}_{\mathrm{PAR}}=\underline{I}_{\mathrm{Q}}+\underline{I}_{\mathrm{T}}
$$

The absolute value of the current $\underline{I}_{\mathrm{PAR}}$ does not exceed $I_{\text {PARmax }}$ :

$$
I_{\mathrm{PAR}}=\sqrt{I_{\mathrm{T}}^{2}+I_{\mathrm{Q}}^{2}} \leq I_{\mathrm{PAR} \max } .
$$

The value of $I_{\text {PAR max }}$ is determined by the maximum value of the injected voltage $U_{\mathrm{T} \max }$ of the serial branch, the nominal voltage of the grid $U_{\mathrm{N}}$ and the maximal apparent power $S_{\max }$ of the UPFC:

$$
I_{\mathrm{PAR} \max }=\frac{U_{\mathrm{T} \max } \cdot S_{\text {max }}}{U_{\mathrm{N}}^{2}}
$$

The maximal power of UPFC is calculated:

$$
S_{\max }=\frac{U_{1} \cdot U_{2}}{X_{1}+X_{2}} \cdot \sin \left(\delta_{12}\right) .
$$

In (8) the value of the angle $\delta_{12}$ between the voltage phasor at the beginning $\underline{U}_{1}$ and at the end $\underline{U}_{2}$ of the line is often chosen 30 degrees. The reactance $X_{1}$ and $X_{2}$ denote the reactance of the line before and after the UPFC.

The nominal $I_{\mathrm{N}}$ current of the UPFC is calculated from the maximal power $S_{\max }$ of the UPFC and the nominal voltage $U_{\mathrm{N}}$ :

$$
I_{\mathrm{N}}=S_{\max } / U_{\mathrm{N}}
$$

The current of the serial branch $I_{\mathrm{UPFC}}$ does not exceed the nominal current $I_{\mathrm{N}}$ :

$$
I_{\mathrm{UPFC}} \leq I_{\mathrm{N}}
$$

By setting the maximum injected voltage $U_{\text {Tmax }}$, the nominal power of the serial branch can be calculated:

$$
S_{\mathrm{N} \text { ser }}=U_{\mathrm{T} \max } \cdot I_{\mathrm{N}} \cdot
$$

The nominal power of the parallel branch is calculated:

$$
S_{\mathrm{N} p a r}=U_{\mathrm{A}} \cdot I_{\mathrm{PAR}}=U_{\mathrm{N}} \cdot I_{\mathrm{N} p a r} .
$$

As the active power of the serial and parallel branch is balanced [12], the value of the nominal power of the serial and the parallel branch is the same $S_{\mathrm{N} \text { ser }}=S_{\mathrm{N}}$ par. It follows that the nominal current $I_{\mathrm{N} \text { par }}$ of the parallel branch is calculated: 


$$
I_{\mathrm{N} \text { par }}=S_{\mathrm{N} \text { par }} / U_{\mathrm{N}} \text {. }
$$

The nominal power $S_{\mathrm{N}}$ of the UPFC is the sum of the nominal power of the serial and the parallel branch:

$$
S_{\mathrm{N}}=S_{\mathrm{N} \text { par }}+S_{\mathrm{N} \text { ser }} \text {. }
$$

A mathematical model for the voltage stability of the EPS is driven based on previous described knowledge of the operation of the UPFC, its parameters $\left(U_{\mathrm{T}}, \varphi_{\mathrm{T}}, B_{\mathrm{Q}}\right)$ and variables.

\section{Derivation of the mathematical model of an UPFC}

The basic mathematical model of the UPFC for voltage stability analysis is presented on the extended SLIB (Single Load Infinity Bus) model, Fig. 2. The UPFC is connected through the $\pi$ model of the transmission line with the parameters $R_{1}, R_{2}, X_{1}, X_{2}, B_{10}$ and $B_{20}$. The SLIB model is suitable for the voltage stability studies in which the voltage dependence of the load bus $U_{2}\left(P_{2}\right)$ is presented, depending on the network conditions (load flows) and the characteristics of the loads [12]. To find out how the device UPFC affects the voltage $\underline{U}_{2}$, the UPFC is placed in the line at an arbitrary distance from the slack, the parameters $R_{1}$ and $R_{2}, X_{1}$ and $X_{2}, B_{10}$ and $B_{20}$ are in general different. By placing an UPFC in the two-bus model, the SLIB model extends to the four-bus model with the UPFC connected between the buses A and B. On the buses A and B the susceptances $B_{10}$ and $B_{20}$ are connected, as shown in Fig. 2.

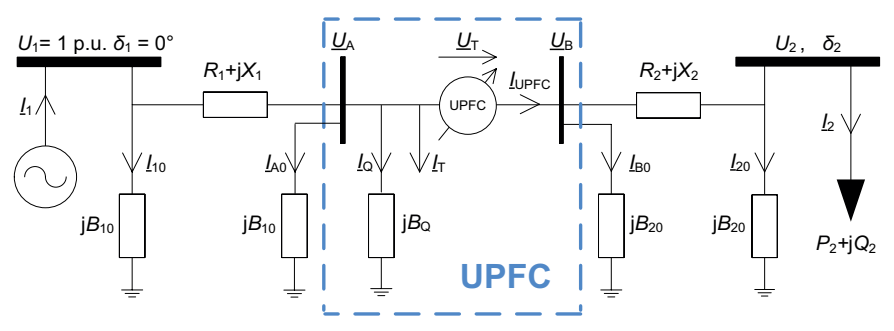

Fig. 2 The SLIB model with the UPFC.

An UPFC is modelled as a continuously controlled injected voltage $\underline{U}_{\mathrm{T}}$ and current $\underline{I}_{\mathrm{Q}}$ with a fast response [10]. The derivation of the analytical equation for the voltage $U_{2}$ with the UPFC is based on the model shown in Fig. 2, for which the Kirchhoff current (15) and voltage (16) laws are described as follows:

$$
\begin{gathered}
\underline{I}_{1}=\underline{I}_{10}+\underline{I}_{\mathrm{A} 0}+\underline{I}_{\mathrm{Q}}+\underline{I}_{\mathrm{T}}+\underline{I}_{\mathrm{B} 0}+\underline{I}_{20}+\underline{I}_{2}, \\
\underline{U}_{2}=\underline{U}_{1}-\left(R_{1}+\mathrm{j} X_{1}\right) \cdot\left(\underline{I}_{\mathrm{A} 0}+\underline{I}_{\mathrm{Q}}+\underline{I}_{\mathrm{T}}+\underline{I}_{\mathrm{B} 0}+\underline{I}_{20}+\underline{I}_{2}\right) . \\
+\underline{U}_{2}-\left(R_{2}+\mathrm{j} X_{2}\right) \cdot\left(\underline{I}_{20} \cdot \underline{I}_{2}\right)
\end{gathered}
$$

The currents in (15) can be substituted with the known variables $P_{2}, Q_{2}, \underline{U}_{1}$, with the parameters of the network: $R_{1}, X_{1}, R_{2}$, $X_{2}, B_{10}, B_{20}$, with the parameters of the UPFC: $U_{\mathrm{T}}, \varphi_{\mathrm{T}}, B_{\mathrm{Q}}$ and with the unknown variable - voltage $U_{2}$. After the analytical derivation the solutions can be presented in the form of two equations:

$$
\begin{gathered}
f_{1}\left(U_{1}, R_{1}, X_{1}, B_{10}, R_{2}, X_{2}, B_{20}, P_{2},\right. \\
\left.U_{\mathrm{T}}, \varphi_{\mathrm{T}}, B_{\mathrm{Q}}, U_{2 \mathrm{Re}}, U_{2 \mathrm{Im}}\right)=0, \\
f_{2}\left(f_{1}, U_{1}, R_{1}, X_{1}, B_{10}, R_{2}, X_{2}, B_{20}, P_{2},\right. \\
\left.U_{\mathrm{T}}, \varphi_{\mathrm{T}}, B_{\mathrm{Q}}, U_{2 \mathrm{Re}}\left(U_{2 \mathrm{Im}}\right), U_{2 \mathrm{Im}}\right)=0,
\end{gathered}
$$

The analytical function (18) consists of two solutions - imaginary part $U_{2 \text { Im }}^{\text {up }}$ of the voltage phasor for the upper $P V$ curve:

$$
\begin{gathered}
U_{2 \mathrm{Im}}^{\text {up }}\left(U_{1}, R_{1}, X_{1}, B_{10}, R_{2}, X_{2}, B_{20}, P_{2},\right. \\
\left.U_{\mathrm{T}}, \varphi_{\mathrm{T}}, B_{\mathrm{Q}}, U_{2 \mathrm{Im}}^{\text {up }(0)}\right)=0
\end{gathered}
$$

and imaginary part $U_{2 \mathrm{Im}}^{\mathrm{low}}$ of the voltage phasor for the lower $P V$ curve:

$$
\begin{gathered}
U_{2 \mathrm{Im}}^{\text {up }}\left(U_{1}, R_{1}, X_{1}, B_{10}, R_{2}, X_{2}, B_{20}, P_{2},\right. \\
\left.U_{\mathrm{T}}, \varphi_{\mathrm{T}}, B_{\mathrm{Q}}, U_{2 \mathrm{Im}}^{\mathrm{low}(0)}\right)=0
\end{gathered}
$$

With the introduction of the solutions (19) and (20) in (17) the voltage phasors for the upper $\underline{U}_{2}^{\text {up }}$ and the lower $\underline{U}_{2}^{\text {low }}$ $P V$ curves are calculated. Determination of the initial values $U_{2 \mathrm{Im}}^{\text {up (0) }}$ and $U_{2 \mathrm{Im}}^{\mathrm{low}(0)}$ are crucial for the calculation of the proper values $\underline{U}_{2}^{\text {up }}$ and $\underline{U}_{2}^{\text {low }}$.

\section{Voltage-stability analysis for the extended SLIB model with the UPFC}

A voltage stability analysis for the extended SLIB model with an UPFC is performed with the calculation of (17-20) iteratively with increasing a value of the load $P_{2}=\lambda \cdot P_{20}$. A voltage collapse occurs when the load factor $\lambda$ takes the maximum value max $\lambda=\lambda_{\max }$ at which the values of the roots of (19) and (20) become imaginary $U_{2} \notin \mathrm{Re}$.

A study of an effect of the UPFC on the voltage stability in the extended SLIB model is based on the nominal power $S_{\mathrm{N}}$, which is also a key indicator for the costs of FACTS devices. The nominal power $S_{\mathrm{N}}=2.5$ p.u. and the nominal current $I_{\mathrm{N}}=2.5$ p.u. of the UPFC are calculated at the values of the reactance $X_{1}=X_{2}=0.1$ p.u., at the nominal voltage $U_{1}=U_{2}=1$ p.u. and at the (maximal) transmission angle $\delta_{12}=30^{\circ}$.

For the numerical calculations, the following values of the line parameters are used; see the model in Fig. 2:

$$
\begin{aligned}
& R_{1}=R_{2}=0.0001 \text { p.u. } \\
& X_{1}=X_{2}=0.1 \text { p.u. } \\
& B_{10}=B_{20}=B_{\mathrm{A} 0}=B_{\mathrm{B} 0}=0.05 \text { p.u. }
\end{aligned}
$$

A linear dependence of the active and reactive power for the load bus $Q_{2}=\mathrm{k} \cdot P_{2}$ is taken. The value of $\mathrm{k}=0.25$ meets the load-power factor $\cos (\varphi)=0.97$. The active load power is increased $P_{2}=\lambda \cdot P_{20}$ from $\lambda_{\min }=0.01$ to the maximum 
value $\lambda_{\max }$ at which the voltage collapse occurs. The slack bus is defined by a constant value of the voltage magnitude $U_{1}=1 \mathrm{p}$.u. and the angle $\delta_{1}=0^{\circ}$. The values of the parameters of the UPFC are:

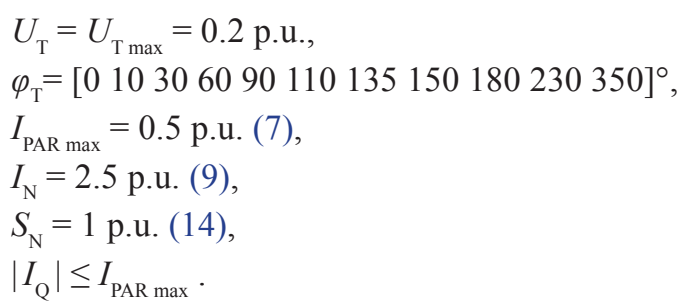

According to a time consuming and the complex calculation of $P V$ curves for the selected parameter values of the UPFC, the values of the angles $\varphi_{\mathrm{T}}$ are selectively chosen by means to demonstrate the operation of the UPFC in each quadrant.

The following initial values and constants are used:

$$
\begin{aligned}
& P_{20}=1 \text { p.u., } \\
& \lambda_{(0)}=\lambda_{\text {min }}=0,01, \\
& B_{Q(0)}=0.0001 \text { p.u. }
\end{aligned}
$$

\subsection{PV Curves for the UPFC}

The results of the simulation $U_{2}\left(P_{2}\right)$ with the UPFC are shown in Fig. 3, where each $P V$ curve corresponds to a specific value of the parameter of the UPFC. The $P V$ curve also known as nose curve consists of an upper $U_{2 \text { UP }}$ and a lower $U_{2 \text { Low }}$ curve. In Fig. 3 . the upper curve are denoted with solid and the lower curve with dotted line. The latter do not satisfy the constraints (6) and (10) which means that are outside the scope of an operation of the UPFC and are limited to a theoretical consideration.

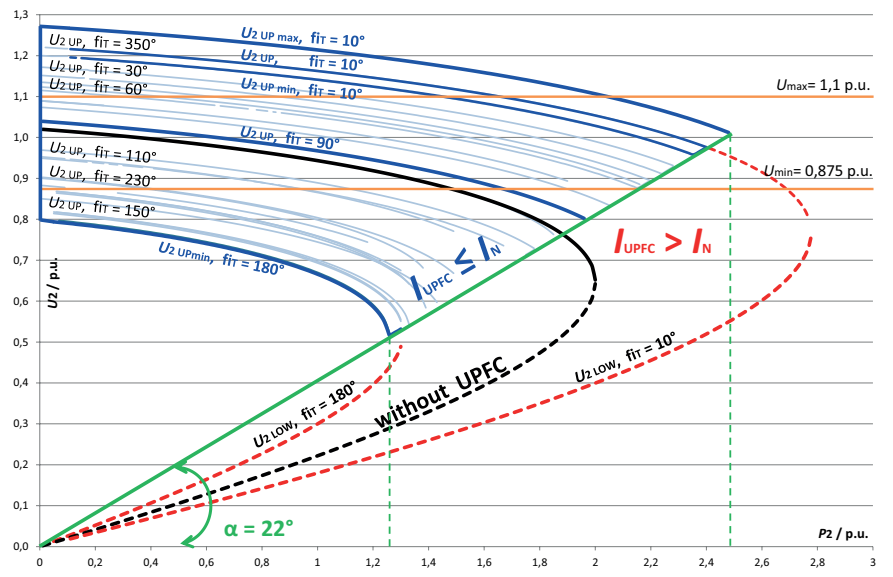

Fig. 3 PV curves for different values of the parameter $\varphi_{\mathrm{T}}$ for SLIB with the UPFC at $U_{\mathrm{T}}=0.2 \mathrm{p} . \mathrm{u}$.

The black curve denotes the voltage $U_{2}$, without the UPFC operation $\left(U_{\mathrm{T}}=0, \varphi_{\mathrm{T}}=0, B_{\mathrm{Q}}=0\right)$ and distinguishes the operation of the UPFC in inductive $\left(90^{\circ}<\varphi_{\mathrm{T}}<270^{\circ}\right)$ and capacitive $\left(0^{\circ}<\varphi_{\mathrm{T}}<90^{\circ}\right.$ and $\left.270^{\circ}<\varphi_{\mathrm{T}}<360^{\circ}\right)$ mode. In Fig. 3 the blue upper curves above the black curve denote an operation in the capacitive mode and below the black curve denote an operation in the inductive mode.
The solutions of (18) enable the calculation of $P V$ curves, which are the basis for the analysis of voltage stability [1]. The upper $U_{2 \text { UP }}$ and the lower $U_{2 \text { Low }} P V$ curve for the model in Fig. 2 is calculated at the constant parameters of the $U_{\mathrm{T}}$, $\varphi_{\mathrm{T}}$ and $B_{\mathrm{Q}}$. By variation of the angle $0^{\circ} \leq \varphi_{\mathrm{T}} \leq 360$ and the injected voltage $0 \leq U_{\mathrm{T}} \leq U_{\mathrm{T} \max }$ at the selected values $B_{\mathrm{Q}}$ the multitude of curves $U_{2}$ up are calculated. Since the parameter $B_{\mathrm{Q}}$ replaces controllable parameter $I_{\mathrm{Q}}$, it can vary in capacitive $B_{\mathrm{Q}}>0$ or inductive $B_{\mathrm{Q}}<0$ mode until the constraints (6) and (10) are satisfied. In case of $B_{\mathrm{Q}}>0$ the maximal upper curve $U_{2 \mathrm{UP} \max }$ is calculated and in case of $B_{\mathrm{Q}}<0$ the minimal upper curve $U_{2 \text { UP min }}$ is calculated. Thus the entire operating range of the UPFC is simulated, that extends the possibility of varying the upper voltage $U_{2 \text { UP }}$ between the voltage $U_{2 \text { UP } \min }$ and $U_{2 \text { UP } \max }$.

The permissible band of the bus voltage in the EPS is set between minimal $U_{\min }=0.875$ p.u. and maximal $U_{\max }=1.1$ p.u. value.

In the Figure 3 the area marked with the blue curves, which is the scope of possible operating regime of the UPFC, is limited with two curves:

- $U_{2 \mathrm{UP} \max }$ at $\varphi_{\mathrm{T}}=10^{\circ}$ and

- $U_{2 \text { UP min }}$ at $\varphi_{\mathrm{T}}=180^{\circ}$,

between them are situated the $P V$ curves calculated at the others angles $\varphi_{\mathrm{T}}$.

Ability of the UPFC for maintaining a voltage stability (at $U_{\mathrm{T}}=0.2$ p.u.) is estimated by observing the voltage range of $\pm \Delta U$ according to the black $P V$ curve when the UPFC is out of operation. Figure 3 shows that:

- at low load (E.g. $P_{2}=0.11$ p.u.) a voltage change up is $+\Delta U=0.25$ p.u. and down is $-\Delta U=0.18$ p.u.

- at high load (E.g. $P_{2}=1.27$ p.u.) a voltage change up is $+\Delta U=0.27$ p.u. and down is $-\Delta U=0.4$ p.u.,

which demonstrates a notable contribution of the UPFC to maintaining a voltage stability in the EPS.

In Figure 3 can be seen that the lower and upper $P V$ curves do not converge in the proximity of the voltage collapse; the reason is the constraint (10).

The result of the operation of the regulation of $I_{\mathrm{Q}}$ at a constant angle $\varphi_{\mathrm{T}}=10^{\circ}$ and an injected voltage $U_{\mathrm{T}}=0.2$ p.u. is illustrated in Fig. 3 with three $P V$ curves:

- $U_{2 \text { UP }}$, fit $=10$; the curve at constant $I_{\mathrm{Q}}=0.0001$ p.u.,

- $U_{2 \text { UP } \max }$, fit $=10$; the curve at $B_{\mathrm{Q}}>0, I_{\mathrm{Q}}$ is increased as long as (6) and (10) are satisfied,

- $U_{2 \text { Low max }}$, fit $=10$; the curve at $B_{\mathrm{Q}}<0, I_{\mathrm{Q}}$ is decreased as long as (6) and (10) are satisfied.

Figure 3 reveals an interesting feature of an UPFC: all peaks of the upper curves end up on the straight line (denoted with green colour) at the angle $\alpha=22^{\circ}$ irrespective of a value of the angle $\varphi_{\mathrm{T}}$. This new finding is verified by another calculation in which the resistance of the lines are increased $R_{1}=R_{2}=0.01$ p.u. The results of re-calculation are shown in Fig. 4. 


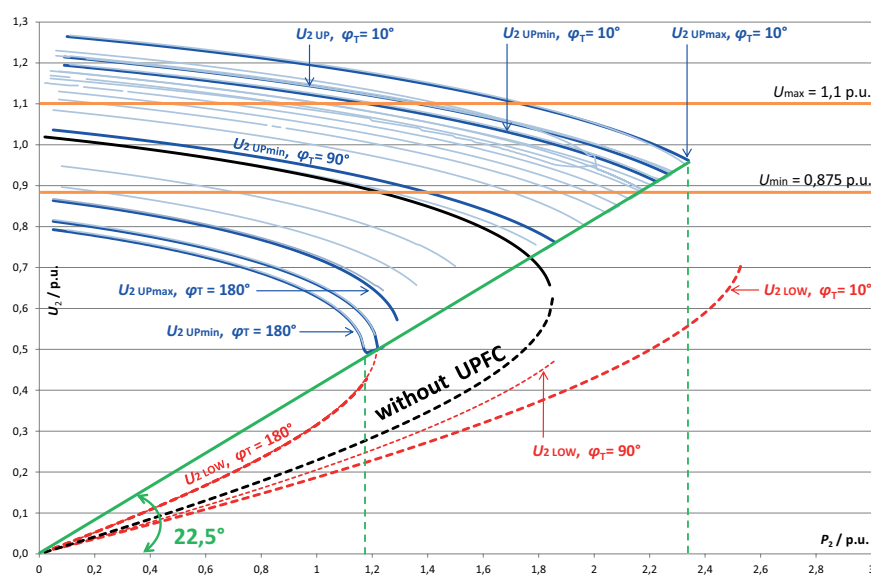

Fig. $4 P V$ curves for different values of the parameter $\varphi_{\mathrm{T}}$ for SLIB with the UPFC at $U_{\mathrm{T}}=0.2$ p.u., $X=0.1$ p.u., $R=0.01$ p.u.

Figure 4 shows that due to increase of the line resistance the voltage range of operation of the UPFC is shorter, which is an expected result, but it is interesting that the slope of the straight line on which all peaks of the upper curves end up is changed only for one half of the angular degree.

Further explanation of the $P V$ curves gives Fig. 5, which shows the current $I_{\mathrm{UPFC}}\left(P_{2}\right)$. The blue curves denote the current $I_{\mathrm{UPFC}}$ at the angle $\varphi_{\mathrm{T}}=10^{\circ}$ and $\varphi_{\mathrm{T}}=180^{\circ}$ at which the maximum and minimum upper curves are calculated, between them are placed the $I_{\mathrm{UPFC}}\left(P_{2}\right)$ curves calculated at the others angles $\varphi_{\mathrm{T}}$.

Figure 5 clearly shows the current limitation (10) of the UPFC at which the current $I_{\mathrm{UPFC}}$ is set to nominal value $I_{\mathrm{N}}=2.5$ p.u. The dotted red curves denote the current $I_{\mathrm{UPFC}}$ at the angle $\varphi_{\mathrm{T}}=10^{\circ}$ and $\varphi_{\mathrm{T}}=180^{\circ}$ corresponding to the lower $P V$ curves. The values of the currents corresponding the lower $P V$ curves are significantly higher than the nominal current $I_{\mathrm{N}}$.

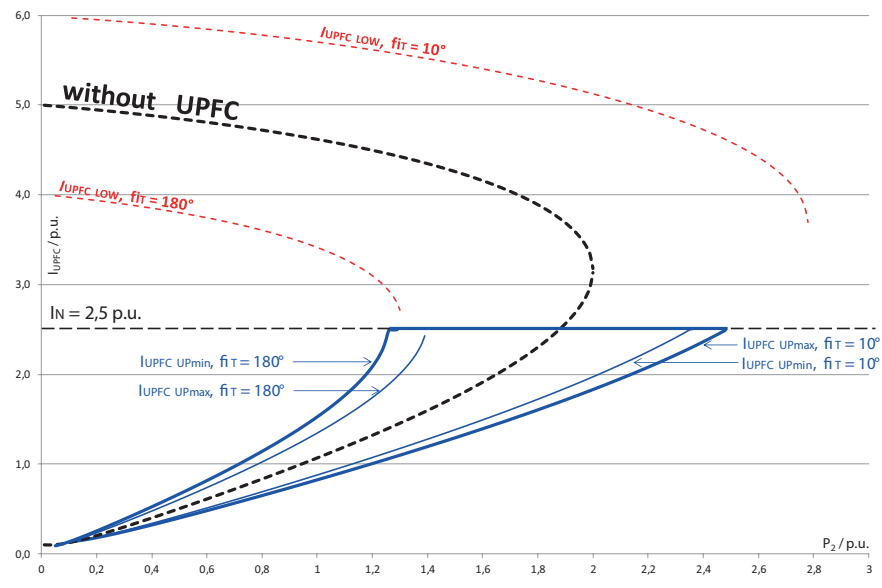

Fig. 5 Maximal and minimal current-power curves for parameter values $\varphi_{\mathrm{T}}=180^{\circ}$ and $\varphi_{\mathrm{T}}=10^{\circ}$ at $U_{\mathrm{T}}=0.2 \mathrm{p} . \mathrm{u}$.

\section{Conclusion}

The motivation for this paper is to present the voltage stability response of a simplified electric power system with an UPFC included. A mathematical derivation of the analytical equations of the $P V$ curves for the extended SLIB model is described and a dependence of load bus voltage $U_{2}$ of the load power, network parameters, and the parameters of an UPFC is shown.

The impact of the UPFC on voltage stability is explained taking into account the possibility of varying all controllable parameters of the UPFC: $U_{\mathrm{T}}, \varphi_{\mathrm{T}}$ and $I_{\mathrm{Q}}$.

Explicit equation for the real and imaginary part of phasor $U_{2}$ allows an insight view into the actual UPFC response on a change of load power $P_{2}$, that classical power-flow programs do not allow.

Based on the analysis of $P V$ curves for different values of the UPFC parameters, we came to the conclusion that the UPFC may have significant influence on voltage stability in the electric power system.

\section{References}

[1] Van Cutsem, T., Vournas, C. "Voltage Stability of Electric Power Systems." New York: Springer Science+Bussines Media. 2008.

[2] Taylor, C. W. "Power System Voltage Stability." New York: Mc Graw Hill. 1994.

[3] Cañizares, C. A. (ed.) "Voltage Stability Assessment: Concepts, Practices and Tools." IEEE-PES

[4] U.S.-Canada Power System Outage Task Force "Final Report on the August 14, 2003 Blackout in the United States and Canada: Causes and Recommendations." 2004.

[5] Elkraft System "Power failure in Eastern Denmark and Southern Sweden on 23 September 2003. Final report on the course of events." 2003.

[6] Younas, M. W., Qureshi, S. A. "Analysis of Blackout of National Grid System of Pakistan in 2006 and the Application of PSS and FACTS Controllers as Remedial Measures." In Electrical Engineering, 2007. ICEE '07. International Conference on. pp. 1-6, 11-12 April 2007. DOI: 10.1109/ICEE.2007.4287339

[7] Vargas, L., Quintana, V. H., Miranda, R. D. "Voltage collapse scenario in the Chilean interconnected system." IEEE Transactions on Power Systems. 14 (4). pp. 1415-1421. 1999. DOI: 10.1109/59.801905

[8] Vournas, C. D., Nikolaidis, V. C., Tassoulis, A. A. "Postmortem Analysis and Data Validation in the Wake of the 2004 Athens Blackout." IEEE Transactions on Power Systems. 21 (3). pp. 1331-1339. 2006. DOI: $10.1109 /$ tpwrs.2006.879252

[9] Gašperič, S., Mihalič, R. "The impact of serial controllable FACTS devices on voltage stability." International Journal of Electrical Power \& Energy Systems. 64. pp. 1040-1048. 2015.

DOI: $10.1016 /$ j.ijepes.2014.08.010

[10] Zhang, X.-P., Retanz, C., Pal, B. "Flexible AC Transmission Systems: Modelling and Control." Springer. 2006. DOI: 10.1007/3-540-30607-2

[11] Hingorani, N. G., Gyugyi, L. "Understanding FACTS, Concepts and Technology of Flexible AC Transmission Systems." IEEE Press. 2000.

[12] Mihalič, R. "Določitev obratovalnih parametrov prečnega transformatorja za izboljšanje obratovalnih razmer in povečanje prenosne zmogljivosti elektroenergetskega sistema." Doctoral thesis. University of Ljubljana, Faculty of Electrical Engineering. 1993. (in Slovenian) 